\title{
OPEN SOURCE FLOOD MAPPING TOOLS - QGIS, RIVER GIS AND HEC-RAS
}

DOI: https://doi.org/10.18509/AGB.2020.04

UDC: 004.457'23.057.8:[528.932:627.512

\section{Catalin Ioan Cimpianu1, Alin Mihu-Pintilie $^{2}$}

\author{
${ }^{1}$ Department of Geography, Faculty of Geography and Geology, \\ Alexandru Ioan Cuza University of Iasi, Romania \\ ${ }^{2}$ Institute for Interdisciplinary Research, Science Research Department, \\ Alexandru Ioan Cuza University of Iasi, Romania
}

corresponding author: mihu.pintilie.alin@gmail.com

\author{
submitted: 05.03.2019 \\ accepted: 01.06.2019 \\ published: 01.09.2019
}

\begin{abstract}
Recently, the area of free and open source geospatial data and software has experienced a significant development and progress. Since the start of geospatial open source "revolution" in the early 2000 (that began with QGIS launching), a transition from commercial software to open source alternatives has been noticed among researchers, professionals, local administrations, etc. This study focuses on using available open source solutions in order to obtain useful information regarding the delineation of flood hazard and flood risk areas. QGIS, a free and open-source geographic information system software was used for spatial data visualization, editing and analysis. River GIS is a QGIS plugin that allows the creation of 1D or 2D geometric flow models using the QGIS environment. A 1D flow model and HEC-RAS software was used to estimate the hydraulics of water flow, delineating the vulnerable areas. Useful information about flood hazard and risk exposure was obtained, the methodology used proved efficient considering the time, cost and the quality of the output. The results managed to capture and delimitate the flood prone areas and the amount of social damages in term of affected persons. Taking into consideration the cost related issues, this methodology can be applied easily by all the interested parties (local communities, local authorities, scientists, responsible persons with flood mitigation) in the development of local, regional or national flood management plans.
\end{abstract}

Keywords: QGIS, HEC-RAS, River-GIS, Flood mapping, Open Source Software

\section{INTRODUCTION}

"Open source" software is defined as software in which the source code is available for modification and redistribution by the general public [1]. Open Source Software (OSS) gained more and more credibility as a large number of initiatives regarding this topic emerged over the last two decades, especially in the GIS market [2,3]. Geospatial open source movement/revolution began as a reply against the numerous limitations imposed by the commercial code (which is traditionally expensive proprietary software) $[4,5]$. In this way, many GIS application capabilities and functionalities were developed and distributed without any usage restriction, being guaranteed for free to the public use. Moreover this phenomenon, gather large communities of users which are working to develop better computer software, leading to continuous progresses and constant updates. The Open Source Geospatial Foundation (OSGeo) is one of the best examples of such community (https://www.osgeo.org). Therefore, as a consequence, many of these applications concentrate on developing software for geographic/spatial data management, storage, analysis and visualization $[2,6]$.

One of the most important open source GIS application developed in the last two decades, is QGIS, software that provides useful GIS tools in spatial analysis, geoprocessing, geometry, and data management tasks [7]. It is one of the most popular open source GIS, offering reliable solutions for public and private sectors like, education, scientific research institutions, non-profit organizations or small business $[8,9]$. This study looks at QGIS and HEC-RAS, both open source software and explores their possibilities to delineate the flood hazard and risk over a given area of interest. This is possible due to RiverGIS, a specially developed tool for creating HEC-RAS flow model geometry inputs in 
QGIS environment. QGIS with RiverGIS is a freeware solution, widely used worldwide that can be perfectly integrated with HEC-RAS software in order to obtain all the geometry parts of the river system, as the main channel, cross-sections, overbanks, flow paths, etc. [10].

One of the most used technique for channel flow analysis and floodplain delineation is the usage of HEC-RAS software [11]. Floodplain studies make usage of hydraulic modeling in order to provide water surface profiles and floodplain maps for

\section{DATA AND METHODS}

QGIS is an Open Source Geographic Information System (GIS) licensed under the GNU General Public License. QGIS is an official project of the Open Source Geospatial Foundation (OSGeo). The project was developed starting from 2002 as a response to the generally expensive GIS proprietary software and the unavailability of this specific type of software as free of cost. Its main purpose is to provide basic GIS functionalities to anyone with access to a computer [4].

The initial goal of the project was to provide a GIS different administrative purposes [12]. The created models (using RiverGIS and HEC-RAS) can reproduce historic water surface elevations recorded during actual flood events [13] but also can be used to develop different scenarios using hypothetical data for flood zoning maps [14]. This paper attempts to highlight the performance of open source software QGIS RiverGIS and HEC-RAS as tools in the flood zoning map development (development of flood hazard and flood risk maps).

data viewer [4], today its capabilities implying viewing, editing, advanced geoprocessing and various analysis possibilities $[15,16]$. Today, QGIS offers many common GIS functionalities provided by its core features (maintained by the QGIS Development Team and part of every QGIS distribution) and plugins (which give the opportunity that new features and functions to be easily added to the application by interested users/developers) [4].

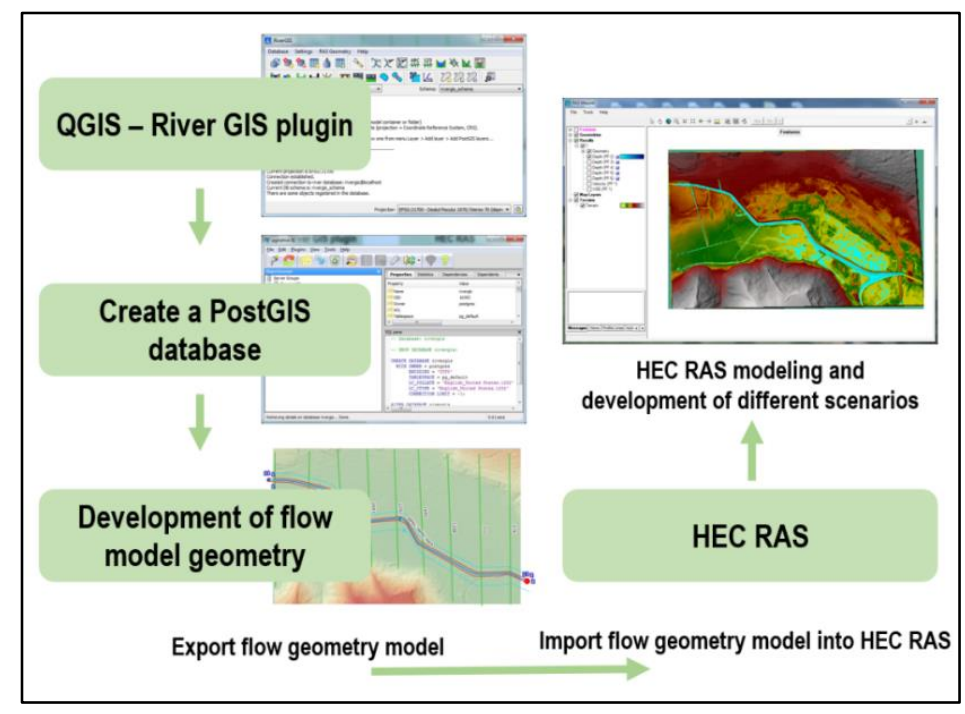

Figure 1. Methodological scheme on how the flood zoning maps were obtained.

QGIS provides a plugin mechanism [17], a Python application program interface (API), which is used to expand its functionality. Since the introduction of this plugin mechanism in QGIS 0.9 in 2007, many tools were added by the developers using Python plugins [18]. The distribution of a plugin is performed using the QGIS official repository, where the developers can upload their work. In this way, the QGIS users can locate it (using QGIS plugin manager) and install it on their computer. All the uploaded plugins fall under GNU General Public License [19].

For data management and tool computation, the present study used the latest QGIS 3.4 Madeira version. RiverGIS is a QGIS plugin developed by
Radosław Pasiok, Łukasz Dębek, Rafał Parda and Karol Zieliński, acting for QGIS as HEC-GeoRAS acts for ArcGIS. It is an excellent alternative that helps you create HEC-RAS flow models in a no cost environment. It brings all the HEC-GeoRAS components into the free/libre software world (http://rivergis.com/about.html). RiverGIS 1.0 version was installed using the Plugin Manager in QGIS. PostgreSQL 9.4 version was installed along with its PostGIS extender. PostGIS is an extension to the PostgreSQL object-relational database system which allows GIS (Geographic Information Systems) objects to be stored in the database [20]. This step was mandatory, as RiverGIS plugin needs a connection to a PostgreSQL database with spatial extensions of PostGIS included 
(http://rivergis.com/about.html). All the necessary data created for the flow model computation were stored in the PostGIS database previously created (Stream Centerlines, XS Cut Lines, Bank Lines, etc.).

After the generation of the flow model geometry, an export for future HEC-RAS hydraulic modeling steps was performed. HEC-RAS (Hydraulic Engineering Centre River Analysis System) is a hydraulic software, developed by US Army Corps of Engineers. It is a tool that can perform steady and unsteady flow simulations and obtain water surface elevations within a specific area of interest [11]. For this study, a 1D steady flow model was used. This assumed that at each cross section established, the water flow proprieties were the same (as entered at the upstream end of the river) and the time variable did not interfered changing this value [21] Figure 1. The flow model and computations were based on a $0.5 \mathrm{~m}$ resolution LiDAR Digital Elevation Model of the study area. The model mapped the areas covered with water taking into consideration the steady flow data introduced (5 profiles). 5 flood zoning maps were developed. The results were then viewed and exported in raster and vector format using the RAS Mapper tool available in HEC-RAS. The last step consisted in the realization of the flood hazard maps and risk assessment evaluation. A full methodological schema regarding the steps performed can be seen in Figure 1.

\section{STUDY AREA}

The study area is located in Iasi, Romania, one of the largest urban area form the county, with a population of almost 350000 inhabitants. For this practical example two of its biggest neighborhoods were selected - Alexandu and Dacia (Figure 2). The

proximity to the Bahlui River and the high population density, make these two neighborhoods vulnerable in the case of a flood event. The selection was based also on the availability of LiDAR data of this region.

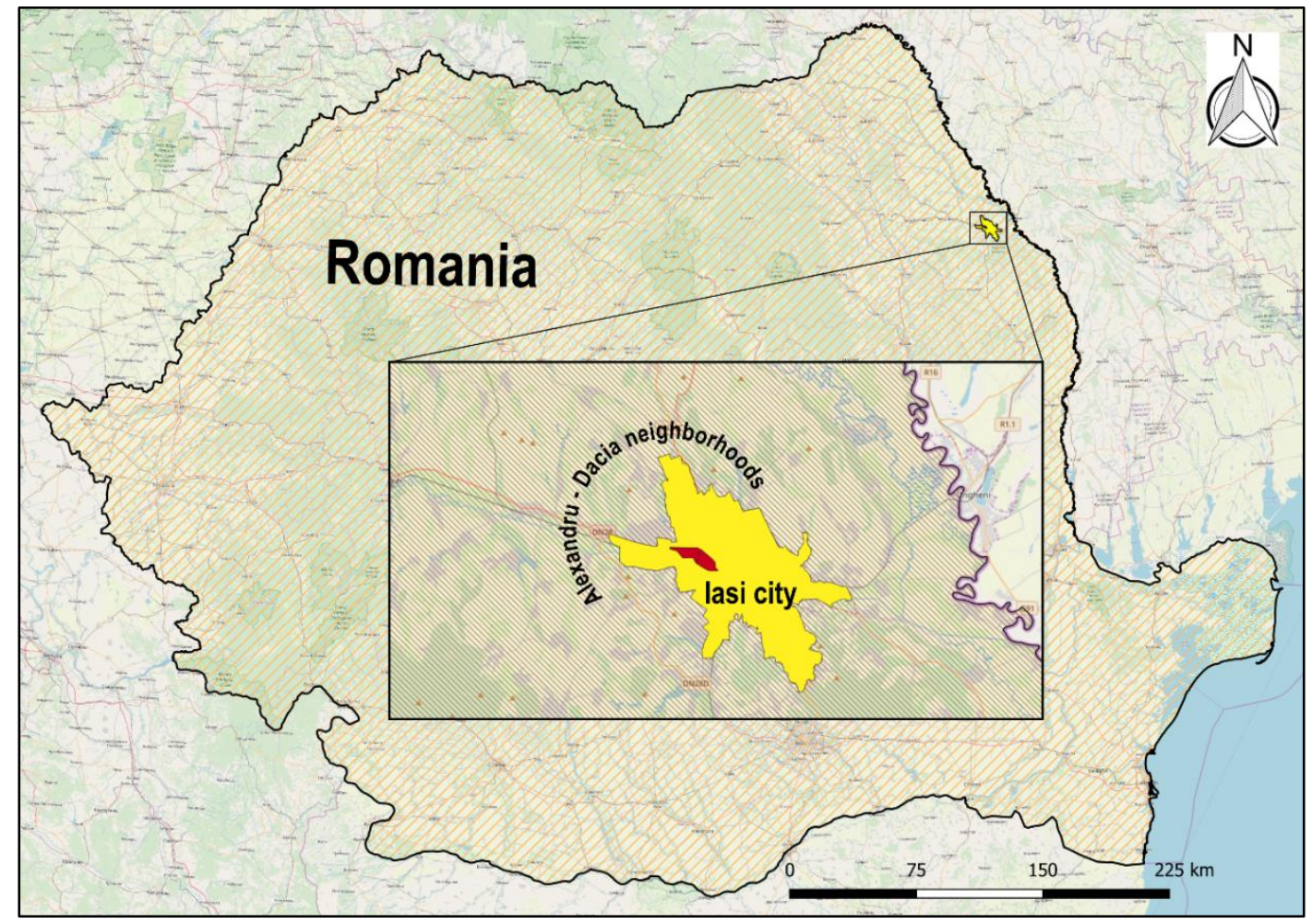

Figure 2. Location of the Study area, Iasi, Romania, Basemap: OpenStreetMap.

\section{RESULTS}

The results consisted in 5 hydraulic simulations which were based on 5 scenarios. Each scenario took into consideration a certain flow rate in the 1D steady flow model used in HEC-RAS computations. Scenario 1 (Figure 3) simulates the river flow in its official average flow rate $(\mathrm{Q}=4 \mathrm{mc} / \mathrm{s})$. This scenario was taken into consideration in order to validate the various hypothetical scenarios proposed. The other scenarios were based on various flow rates as: Scenario $2-\mathrm{Q}=50 \mathrm{mc} / \mathrm{s}$; Scenario $3-\mathrm{Q}=100 \mathrm{mc} / \mathrm{s}$; Scenario $4-\mathrm{Q}=300 \mathrm{mc} / \mathrm{s}$; Scenario $5-\mathrm{Q}=500 \mathrm{mc} / \mathrm{s}$.
The identification of the risk assessment was realized by intersecting the flood hazard extend map obtained in Scenario 2 with the buildings and addresses layer of the neighborhoods (study area) (Figure 8). A number of 111 building were reported as affected by the flood extend (proposed by Scenario 2 with an average $\mathrm{Q}=50 \mathrm{mc} / \mathrm{s}$ ) cumulating a number of over 10000 individuals (in terms of affected persons). The cartographical materials (flood hazard maps and flood risk map) were realized using expressly QGIS environment. 


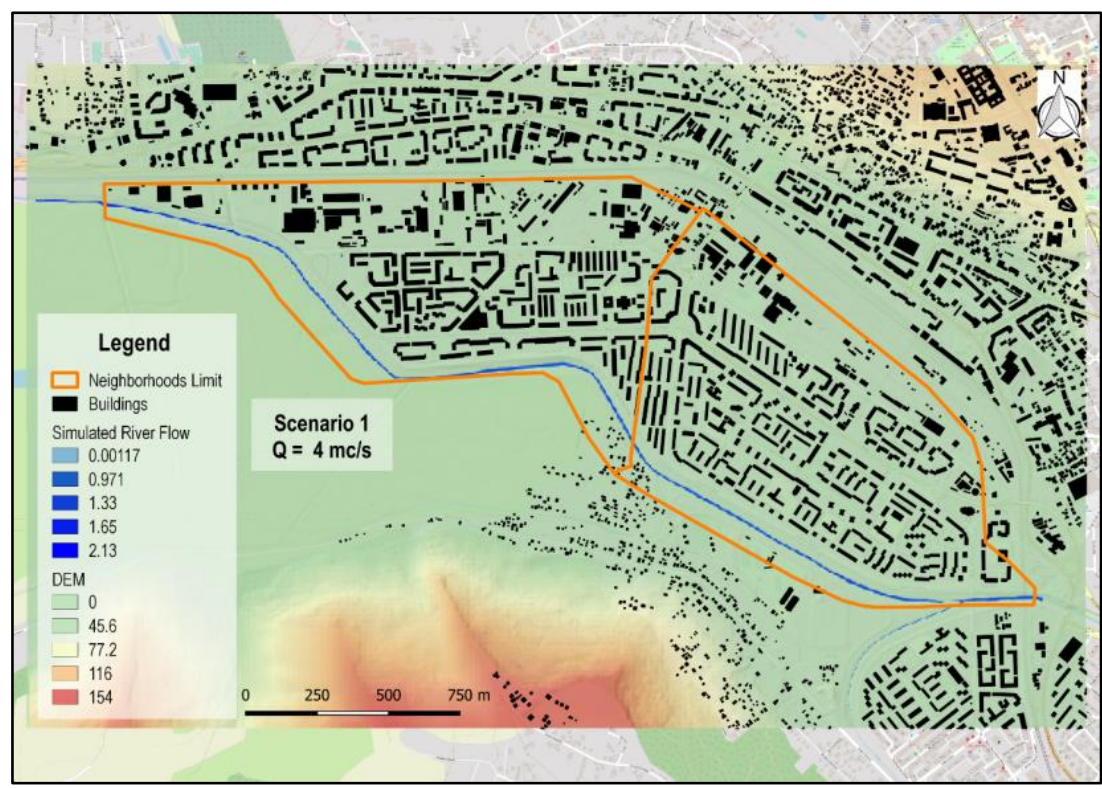

Figure 2. Scenario 1, Q=4mc/s, Basemap: OpenStreetMap.

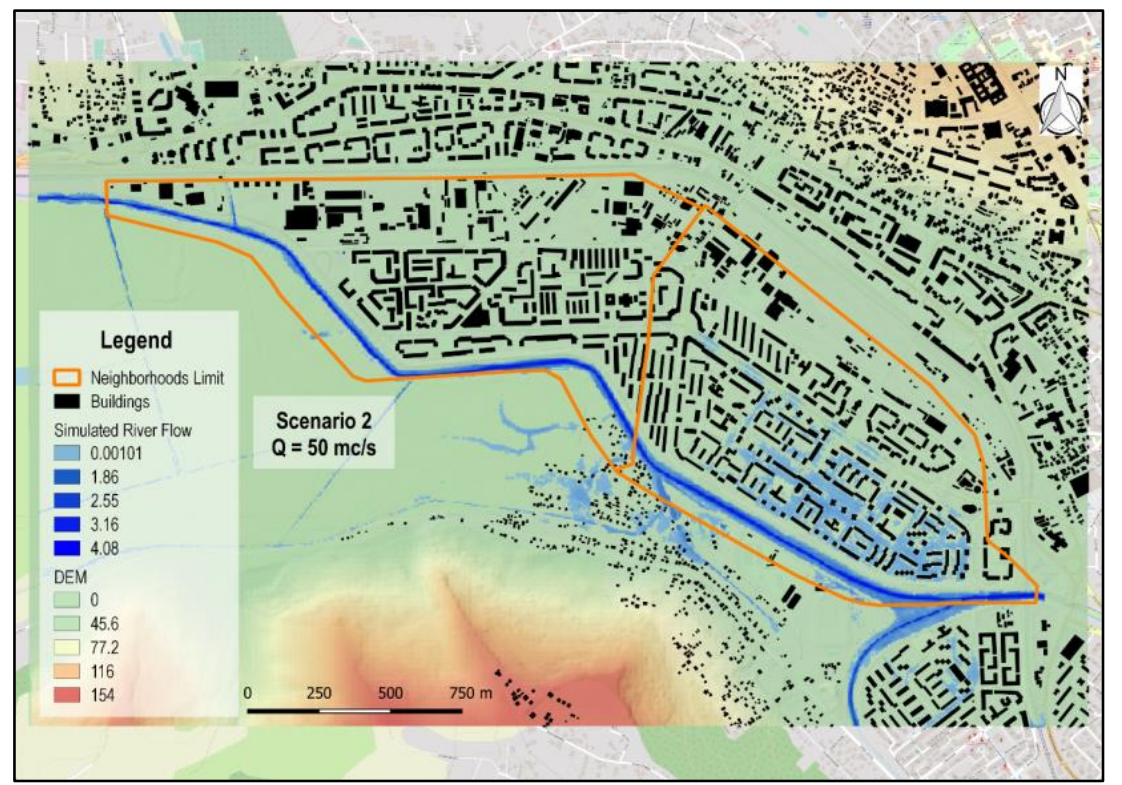

Figure 3. Scenario 2, Q=50mc/s, Basemap: OpenStreetMap.

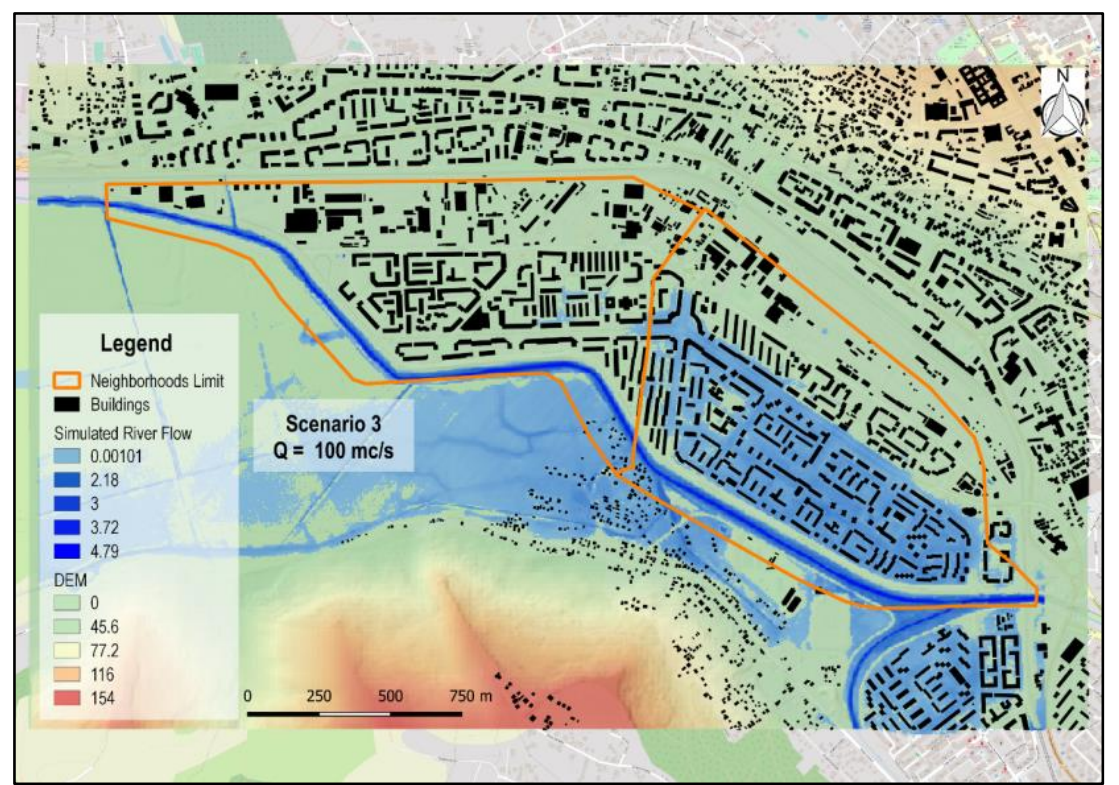

Figure 4. Scenario 3, Q=100ms/s, Basemap: OpenStreetMap. 


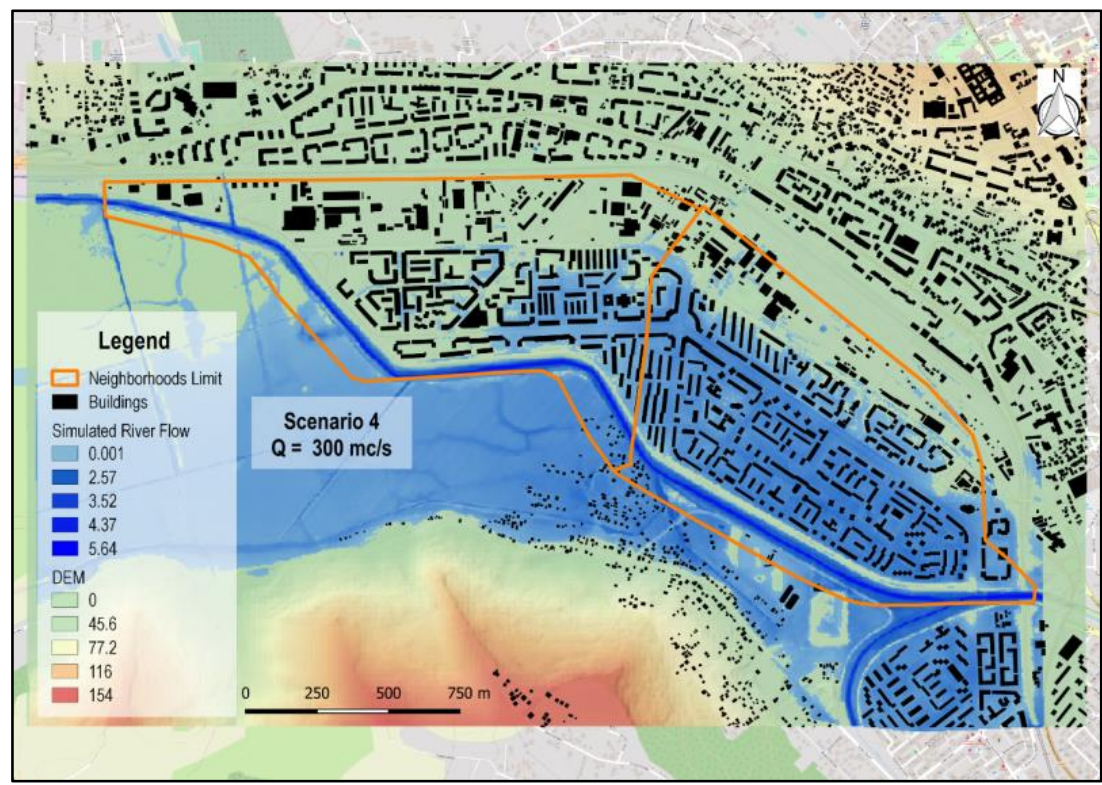

Figure 5. Scenario 4, Q=300mc/s, Basemap: OpenStreetMap.

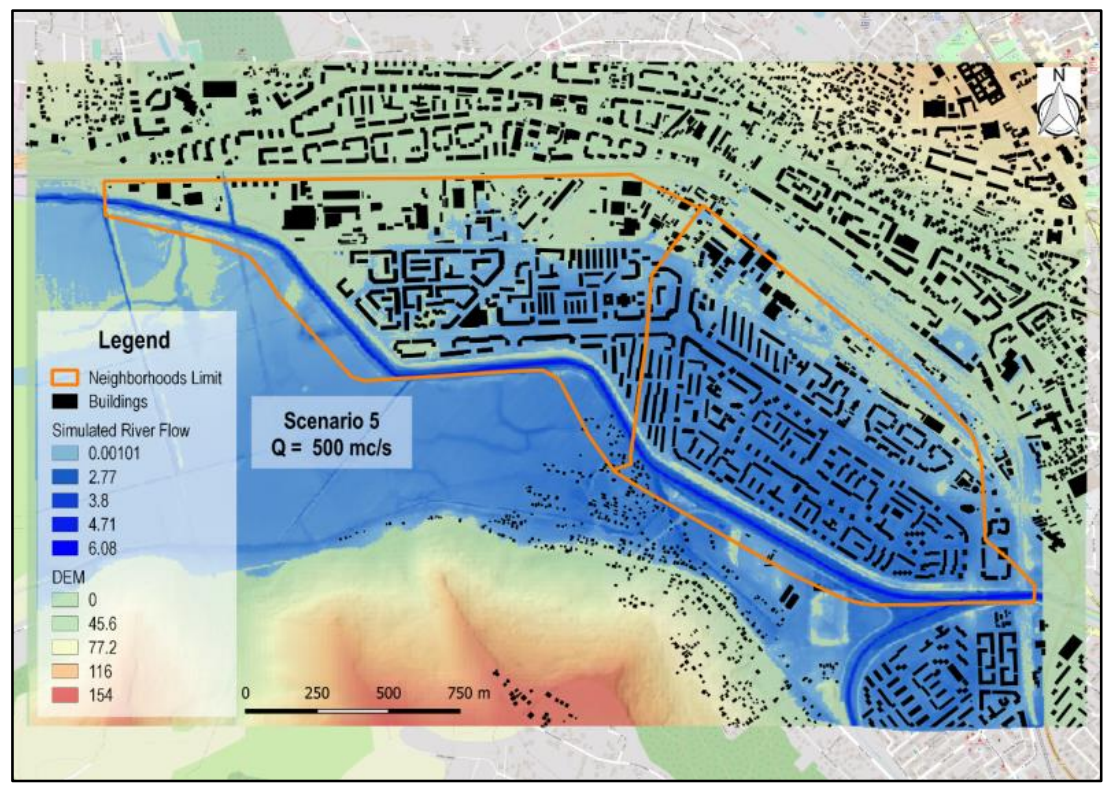

Figure 6: Scenario 5, Q=500mc/s, Basemap: OpenStreetMap.

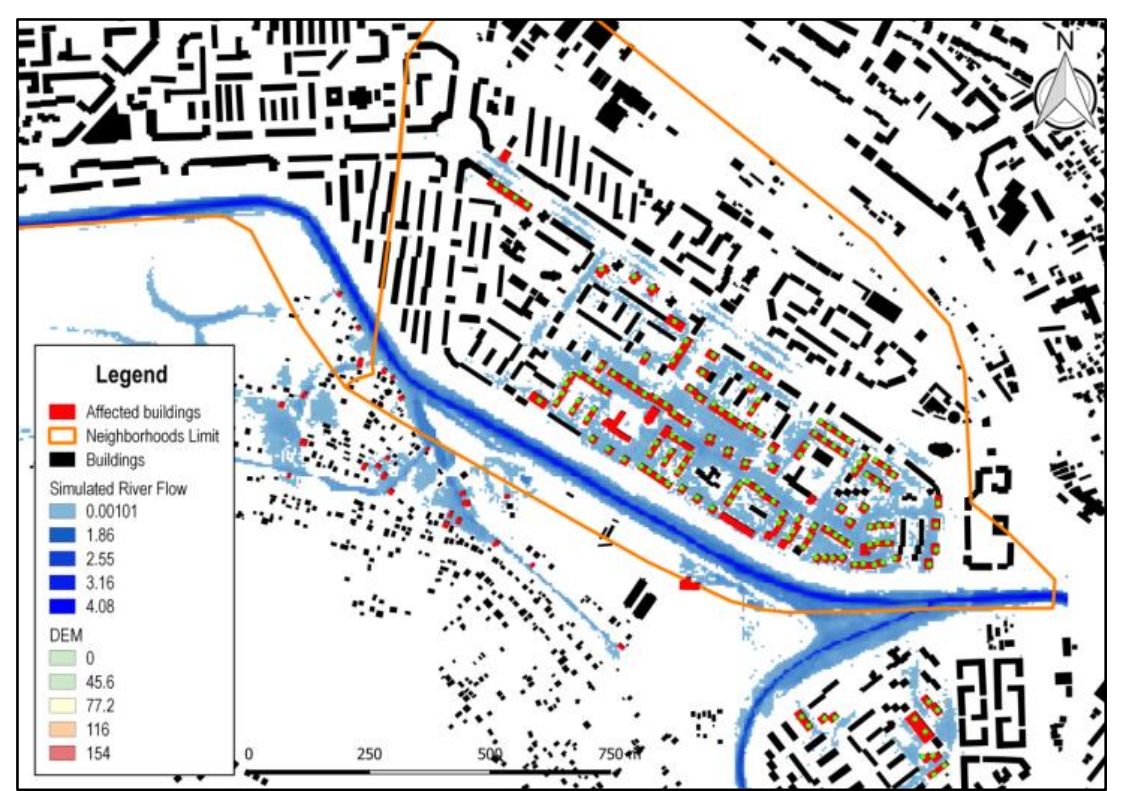

Figure 7: Flood risk map of the study area taking into consideration the Scenario 2. 


\section{CONCLUSIONS}

Open source software, QGIS, RiverGIS plugin and HEC-RAS proved to be very efficient tools in the process of flood hazard and flood risk mapping. The methodology proposed by this study can be easily extrapolated and applied to any region characterized by a reasonable Digital Elevation Model availability. The future of open source GIS (QGIS in particularly), is likely to be bright, as its performance are improving constantly, becoming more and more precise (with a constant addition of new functionalities). This application presented in the current study and this combination of open source software, demonstrate one more time that mapping and development of geospatial data projects is accessible to anyone with basic GIS knowledge and access to a computer. This is a big step forward for local administrations, researchers, persons responsible with emergency situations which can use these free tools to a better management of flood hazard and risk. Developing scenarios (like the ones presented in this study) can lead to a better planning in case of a flood event occurrence. Production of flood hazard and risk maps is a technique that can be used to improve the training process of the vulnerable people and can teach them how to act in such cases. Another important aspect that can be learned by the population is their vulnerability degree. This means, a faster response in case of an emergency, as well as, more appropriate reaction from the population and increasing security.

\section{ACKNOWLEDGMENT}

This work was funded by the Ministry of Research and Innovation within Program 1 - Development of the national RD system, Subprogram 1.2 - Institutional Performance - RDI excellence funding projects, Contract no.34PFE/19.10.2018 (beneficiary: Alin Mihu-Pintilie). Also, our thanks go to the Head of Geoarchaeology Laboratory within the Faculty of Geography and Geology, Department of Geography, "Alexandru Ioan Cuza" University of Iasi - Romania, which provided the equipment for data processing.

\section{REFERENCES}

[1] Ramsey, P., The state of open source GIS. Presentation at FOSS4G 2007 Conference, Vancouver, BC, Canada, 2007. Available from: refractions.net/expertise/whitepapers/, accessed: 16 February 2019.

[2] Steiniger, S. \& Hunter A.J.S., The 2012 free and open source GIS software map - A guide to facilitate research, development, and adoption, Computers, Environment and Urban Systems, 39, 136-150, ISSN 0198-9715, 2013.

[3] Steiniger, S. \& Bocher, E., An Overview on Current Free and Open Source Desktop GIS Developments, International Journal of Geographical Information Science, 23:10, 1345-1370, 2009.

[4] QGIS Development Team (YEAR). QGIS Geographic Information System. Open Source Geospatial Foundation Project. http://qgis.osgeo.org

[5] Carillo, K., \& Okoli, C., The open source movement: A revolution in software development. Journal of Computer Information Systems. 49. 1-9, 2008.

[6] Rey, S. J., Show me the code: spatial analysis and open source. Journal of Geographical Systems, 11(2), 191-207, 2009.

[7] Ming-Hsiang Tsou \& Smith, J., Free and Open Source Software for GIS education, Department of Geography, San Diego State University, 2011, http://www.iapad.org/wp-content/uploads/2015/07/tsou_free-GIS-for-educatorswhitepaper.pdf.

[8] Graser, A., \& Olaya, V., Processing: A Python Framework for the Seamless Integration of Geoprocessing Tools in QGIS, ISPRS Int. J. Geo-Inf., 4(4), 2219-2245; doi:10.3390/ijgi4042219, 2015.

[9] Van Hoesen, J., Menke, K., Smith, R., \& Davis, P., Introduction to Geospatial Technology Using QGIS. Available online: https://www.canvas.net/browse/delmarcollege/courses/introduction-to-geospatial-technology-1 (accessed on 16 February 2019).

[10] Rubiu, F., Flood risk assessment in the vicinity of Kartena town using HEC-RAS 1D-2D models, Master's degree thesis, Aleksandras Stulginskis University, Faculty of Water and Land Management Institute of Water Resources Engineering 2018.

[11] United States Army Corps of Engineers (USACE): Hydraulic Reference Manual v.4.1. Hydraulic Engineering Center, USA (2010).

[12] Hakim Farooq Ahmad, Akhtar Alam, M. Sultan Bhat, \& Shabir Ahmad, One Dimensional Steady Flow Analysis Using HEC-RAS - A case of River Jhelum, Jammu and Kashmir, European Scientific Journal November, edition vol.12, No.32 ISSN: 1857 - 7881 (Print) e - ISSN 1857- 7431, doi: 10.19044/esj.2016.v12n32p340, 2016.

[13] Christiansen, D. E., \& Eash, D.A., "Flood-Plain Study of the Upper Iowa River in the Vicinity of Decorah, Iowa" USGS Report, 2008. 
[14] Heydari, Mohammad \& Shahiri Parsa, Ahmad \& Sadeghian, Mohammad \& Moharrampour, Mahdi, Flood Zoning Simulation by HEC-RAS Model (Case Study: Johor River-Kota Tinggi Region). Journal of River Engineerin, 1, 2013.

[15] Graser, A. Learning QGIS, 2nd ed.; Packt Publishing: Birmingham, UK, 2014.

[16] Cutts, A., Graser, A., Learn QGIS - Fourth Edition, November 2018.

[17] Hugentobler M., Quantum GIS. In: Shekhar S., Xiong H. (eds) Encyclopedia of GIS. Springer, Boston, MA, DOI https://doi.org/10.1007/978-0-387-35973-1, Publisher Name Springer, Boston, MA, Print ISBN - 978-0-387-308586, 2008.

[18] Graser, A., \& Olaya V., Processing: A Python Framework for the Seamless Integration of Geoprocessing Tools in QGIS, ISPRS Int. J. Geo-Inf., 4(4), 2219-2245, 2015.

[19] Lawhead, J., QGIS Python Programming Cookbook, Publisher Packt Publishing Ltd, ISBN 1787121100, 9781787121102, Length 464 pages, 2017.

[20] Ramsey, P. PostGIS Manual, available at: http://www.dcc.fc.up.pt/ michel/ TABD/postgis.pdf

[21] Hicks, F.E. \& Peacock, T., "Suitability of HEC-RAS for Flood Forecasting" Canadian Water Resources Journal Vol. 30(2): 159-174. Greener Journal of Science, Engineering and Technology Research ISSN: 2276-7835 Vol. 3 (3), pp. 076-081, 2005. 